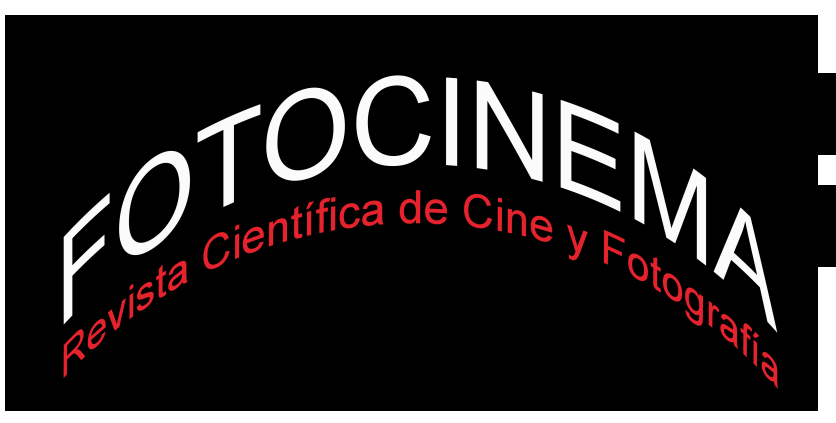

\title{
LAS OCHO VIDAS DE ULYSSES GRANT: EL MITO Y EL RELATO CINEMATOGRÁFICOS
}

\section{THE EIGHT LIVES OF ULYSSES GRANT: THE MYTH AND THE STORY FILM}

\section{Luis Fernando de Iturrate Cárdenes. Universidad de La Laguna, España liturrat@ull.es}

\author{
David Fuentefria Rodríguez. \\ Universidad de La Laguna, España \\ dfuentef@ull.es
}

\section{Resumen:}

Representada tanto o más que el resto de los mandatarios norteamericanos de todas las épocas, la figura del presidente Ulysses S. Grant no ha contado hasta el momento con un amplio predicamento en los estudios de cine, pese a haberse erigido, con idéntica continuidad, en icono singular, tanto de las principales virtudes como del particular carisma del pueblo estadounidense. Muchas han sido las películas y series de televisión que han retratado la trayectoria irregular del dirigente, tan reconocido por sus capacidades para la estrategia militar como vilipendiado por los casos de corrupción que salpicaron los últimos años de su mandato. A través del análisis narrativo, estético y dialógico de sus comparecencias cinematográficas esenciales, este estudio aúna y pone en valor, por vez primera, todas las perspectivas en torno a un personaje histórico cuyos vicios y excelencias quiso combinar el séptimo arte, configurándolo, con el correr de las décadas, como un símbolo único con ribetes de leyenda.

\begin{abstract}
:
Represented much or more than the rest of the American Presidents of all times, the figure of President Ulysses S. Grant has not counted so far with a large predicament in film studies, despite it have been erected, with identical continuity, a singular icon, both the main virtues and the particular charism of the American people. Many have been the films and television series that have portrayed the irregular path of this leader, so renowned for its capabilities for military strategy as reviled by cases of corruption that splashed the last years of his mandate. Through the narrative, aesthetic analysis and Dialogic of their essential film appearances, this study combines and put in value, for the first time, all perspectives on a historical character whose flaws and excellencies wished to combine the seventh art, setting it up, with the passing of decades, as a unique and legend-edged symbol.
\end{abstract}

Palabras clave:

Ulysses Grant; western; mito; biopic; relato.

Keywords:

Ulysses Grant; Western; Myth; Biopic; Story. 


\section{Introducción. Estados Unidos como "forja de hombres". Personajes reales y héroes de ficción}

Es bien sabido que el férreo sentimiento nacional, y la organización de la sociedad y la cultura de los Estados Unidos de América, deben su histórico devenir al asentamiento progresivo de una religión civil -bajo el palio conceptual roussoniano, pero de naturaleza particular- que, desde sus inicios, aglutina tanto el sentir de las mayorías populares como el de las más pudientes, y en el que, a la larga, figuras como las de los Presidentes de la Nación, o las de sus Padres Fundadores, han venido a integrar, con el fervor de sus comunidades religiosas seminales, el sentimiento individual de pertenencia al país, así como el pragmatismo y la determinación en su desarrollo colectivo. Así lo entienden determinados autores como SánchezBayón (2005, p. 266), cuando establecen que "los EEUU surgen de unas bases populares de una gran religiosidad tradicional, pero en pleno proceso secularizador, lo que es aprovechado por las elites político-jurídicas para orientar coyunturalmente la configuración de la identidad nacional y del modelo socio-cultural estadounidense”.

El mismo autor cataloga como ejemplos de elementos religiosos tradicionales secularizados, y orientados por las mismas elites para la creación del modelo USA de convivencia, una serie de elementos psicológicos con correlato en las religiones tradicionales (el temor de Dios o el mesianismo), pero también los símbolos, ritos y creencias que (en ocasiones por sus radicales diferencias) resultan más reconocibles en el Viejo Continente por su exhibición cultural. En este caso, abarcarían desde la Declaración de Independencia y la Constitución del país (trufadas de referencias religiosas) a la Oración del Congreso, el Día del Presidente o los “American values” democristianos.

No es de extrañar, por todo ello, que, con idéntica visión idólatra, y en la misma forja tendente a esa pertinente construcción del ciudadano, el cine estadounidense haya, por lo general, encumbrado a todos aquellos que lograron escribir sus apellidos con letras de oro en algún párrafo de su dilatada historia. Sucede además que, a pesar de que quienes destacaron por sus aportaciones al conocimiento y la cultura del país son los que, a la postre, han tenido menos presencia en el celuloide, tampoco resulta difícil 
comprobar cómo, cuando esta presencia se ha hecho efectiva, sus figuras se han mostrado idealizadas en el marco de valores como la valentía o el heroísmo, muy lejos de las realidades biográficas que en verdad las caracterizaron.

De hecho, los norteamericanos han convertido en héroes a sus forajidos más conocidos, pero también a representantes de la ley cuya realidad histórica poco tuvo que ver con la épica de los lances glosados por la gran pantalla. Dentro del primer grupo, hablamos de "héroes" que en la vida real formaron parte de la trastienda más oscura de sus sociedades, como atestiguan los casos de Henry McCarty ("Billy El Niño"), o las castas de los hermanos James, Jungler o Dalton. En el otro extremo, se incluyen agentes del orden cuyo compromiso con la Ley no reconoce la Historiografía con relevancias excesivas, pero que han alcanzado, gracias al cine, el status de auténticos mitos, como sucediera, por ejemplo, con Elliot Ness y su grupo de "Intocables", o bien con Pat Garrett, Wyatt Earp o John Holliday. Y cabe todavía un último grupo: el de aquellos cuya popularidad y reconocimiento en el imaginario cinematográfico han alcanzado cotas que en la práctica difuminan casi la frontera entre el personaje real y el personaje de ficción: apélese, en este punto, tanto al nostálgico Shane de Raíces profundas (Shane, George Stevens, 1961) como al malvado Liberty Valance (The man who shot Liberty Valance, John Ford, 1963)

Con estos mimbres, cabe esperar que en la construcción mitificadora de los grandes héroes norteamericanos figuren por defecto la mayoría de los inquilinos de La Casa Blanca. Los presidentes de los Estados Unidos en el cine se han exhibido, eso sí, conforme a una multiplicidad de connotaciones, aunque la mayoría conexas a las citadas cualidades de honor y coraje, por encima de las coadyuvantes a la mejora de las condiciones sociales, culturales y políticas del país por las que fueron elegidos en las urnas. Otro tanto sucede con los presidentes de ficción, ensalzados al igual que los reales bajo el mismo constructo psicológico en torno a su personalidad patriótica o sus habilidades como estrategas a lo largo de toda la cinematografía estadounidense. Acaso en los últimos años, es cierto, y debido al reciente devenir histórico, surge una neovisión mucho más crítica en torno al 
"hombre más poderoso del mundo", que alcanza incluso conceptualmente al arquetipo de mandatario, y que no deja bien parados a los presidentes reales de las últimas décadas, ni aun a los ficticios, que en su caracterización por los guionistas apenas pueden evitar -cuando no se convierten en el blanco directo de las críticas- ser el reflejo de alguno de los más polémicos gobernantes de la primera potencia mundial, y de muchas de sus discutidas decisiones.

Si hubiera que localizar, con todo, un punto de inflexión a través del cual comienza a "humanizarse" a los presidentes norteamericanos en el cine, hasta el punto de exponer con toda crudeza sus desaciertos, sin duda habría que retrotraerse hasta la Guerra de Vietnam (1959-1975). Después de este último año, y tras la retirada de las tropas estadounidenses de Saigón, una ola de pesimismo se extendió por toda la nación, hallando el posterior reflejo cinematográfico en la desastrosa gestión de Richard Nixon, y en su implicación en el caso "Watergate".

\section{Marco Teórico: Ulysses Grant. Aproximación histórica en clave de "western"}

De todos los presidentes que ejercieron su mandato en plena Conquista del Oeste hasta que las fronteras quedaron definitivamente cerradas, fue sin duda Ulysses Grant el que más se menciona dentro del "western”, por la coincidencia de su mandato con la construcción del Ferrocarril, que se inició el 1 de julio de 1862, y terminó en 1870 cambiando para siempre las condiciones de vida de los habitantes de aquellas tierras y de sus asentamientos. En concreto, Grant fue presidente en el último tramo temporal de este acontecimiento clave, mientras los demás mandatarios (Abraham Lincoln, 1861-1865, y Andrew Johnson, 1865-1869) cuentan con menos presencia en el citado género, aunque no son pocos, precisamente, los "biopics" que abrazan la vida y obra de Lincoln, tradicionalmente el presidente más querido por los estadounidenses.

Hiram Ulysses Grant (27 de abril de 1822-23 de julio de 1885) fue el decimoctavo mandatario del país, a lo largo de dos legislaturas (1869-1877), y 
participó activamente en la Guerra Civil, aunque la vocación no guió exactamente su fulgurante carrera militar. Resulta curioso examinar sus Memorias, de las que se deduce su diatriba interior, a caballo entre el miedo al fracaso y sus imparables ganas de viajar, que finalmente le conducirían a West Point. Con humor, Grant (2002, pp. 21-22) resaltaba: "I really had no objection to going to West Point, except that I had a very exalted idea of the acquirements necessary to get through. I did not believe I possessed them, and could not bear the idea of failing". Y, más tarde: "Besides the argument used by my father in favor of my going to West Point -that "he thought I would go"- there was another very strong inducement. I had always a great desire to travel".
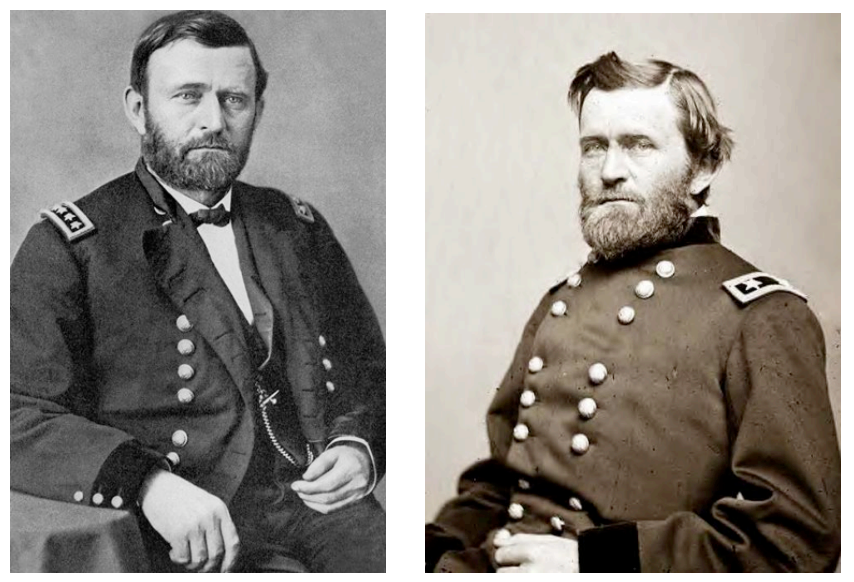

Ávido lector de novelas durante su estancia en la Academia, más que de manuales militares (aseguraba ser incapaz de leer dos veces la misma lección), Grant era impulsivo y no solía admitir que la acción se demorase, y menos frente a disquisiciones teóricas. Pese a reconocer que sus últimos años de instrucción pasaron más rápido para él, el futuro presidente nunca dejó de hablar desapasionadamente de sus exámenes, mas no del ansia por entrar en el ejercicio activo de sus funciones.

En la misma época, comenzaría a forjarse una de las principales leyendas que han rodeado la representación cinematográfica de Grant: la de su pretendido desaliño. Las crónicas cuentan que en West Point acusaba frecuentemente negligencia en el atuendo, lo que choca con el pasaje de sus recuerdos en que rememora la impaciencia con que tuvo que esperar para dar la orden de confeccionar su uniforme, una vez completada la instrucción, mientras no 
recibiera asignación militar. En concreto, Grant saber cómo le quedaría, y por mostrarse ante sus viejos compañeros de escuela, particularmente las chicas.

Más en la leyenda que en los documentos oficiales hay que buscar también apoyo para detectar el otro gran rasgo característico de la construcción mítica del personaje: su afición por la bebida, contraída durante la estancia de Grant, a partir de 1852, en Fort Vancouver, una localidad fronteriza y aislada en Oregón, junto al río Columbia, epítome de las rutinas y monotonías de la vida militar, que acentuaron la soledad y el sentimiento de lejanía de la familia. Pese a que, en el cine, el mal hábito contribuiría a moldear al personaje tras la persona, en la realidad le trajo graves problemas, como el ultimátum planteado por su superior, el coronel Buchanan, durante la estancia del futuro presidente en Fort Humboldt, dos años después, que le obligaba a presentar su dimisión o comparecer ante un tribunal tras haber sido hallado ebrio en público.

Sin embargo, el ascenso de quien sería conocido como "Butcher Grant" (no contaba sus muertos, pero era incapaz de cazar un pájaro) no estuvo exento de obstáculos. Ataques de los puritanos o acusaciones de negligencia que serían remedadas por el propio presidente Lincoln se cuentan entre sus principales luchas internas, que sus victorias en el campo de batalla terminaría acallando poco a poco, como en los casos de Vicksburg (1863), que le supuso la Medalla del Congreso.

Ulysses ganó con tan solo 46 años, dentro del Partido Republicano, la presidencia de los Estados Unidos y el récord de ser el inquilino más joven de la Casa Blanca en el año 1869, y se marchó, concluida una segunda legislatura, tras su reelección en 1872, bajo la sombra de la sospecha y el rechazo popular por la elevada corrupción que marcó este período, y también por la crisis económica que siguió a su renovación en el cargo.

Cabe destacar que las Memorias aquí citadas servirían a Grant a la postre para sacarle de la bancarrota en sus últimos años, y que dicho documento autobiográfico ha recibido la consideración, por parte de la crítica 
estadounidense, como el mejor escrito jamás por un comandante de Estados Unidos.

\section{Ulysses Grant en el cine. Hipótesis única y metodología}

Este trabajo pretende demostrar una única hipótesis: que la reiteración y el tratamiento en el cine de la figura de Ulysses Grant vienen acompañados, de un modo exclusivo, de la mitificación paradigmática que, a la postre, puede encontrarse en el resto de los presidentes norteamericanos hasta la Guerra de Vietnam. Dicha mitificación abarca los procesos más obvios de su construcción histórica como personaje (el arrojo al frente de las tropas) como los más sutiles, hasta el punto de que en todas sus apariciones cinematográficas sus vicios aparecen transmutados en virtudes (el más evidente, de hecho, su alcoholismo, aparece siempre revestido de un aura de reflexión, autoridad o identidad en sentido positivo).

Para ello, vamos a ajustarnos a una taxonomía que incluirá una nutrida selección de películas escogidas conforme a criterios estrictos de:

1) Relevancia histórica, es decir, que por su capacidad de penetración en el imaginario colectivo permanecen aún en él de un modo u otro.

2) Superación de fronteras, o lo que es lo mismo, que trascendieran más allá de sus países de origen, y se distinguieran en otras latitudes.

Ello es así en tanto que parece claro que (Astre, Hoarau, 1997, p. 203) "se pueden disociar, efectivamente, cuando se trata del 'western', las 'obras maestras' del género, debidas a cierto realizador de gran talento, y esta masa impresionante de películas medianas o mediocres, que constituyen en cierto modo el campo cultural indispensable”.

Así, el material audiovisual que vendría a componer dicha taxonomía, ajustada a los citados criterios, es el siguiente:

1) Unión Pacífico (Cecil B. DeMille, 1939).

2) Murieron con las botas puestas (Raoul Walsh, 1941).

3) Río de plata (Raoul Walsh, 1948).

4) Tambores de guerra (Delmer Daves, 1954). 
5) Mision de audaces (John Ford, 1959).

6) La conquista del Oeste (John Ford, Henry Hathaway, George Marshall, Richard Thorpe, 1962).

7) La leyenda del Llanero solitario (Richard A. Fraker, 1981).

8) Lincoln (Steven Spielberg, 2012).

\subsection{Unión Pacifico}

\subsubsection{Un actor, un presidente}

Antes de entrar en materia, conviene detenernos en el rostro por excelencia de Ulysses Grant dentro de la cinematografía americana: Joseph Crehan nació el 15 de julio de 1883 en Baltimore (Maryland), y comenzó a actuar en teatros regionales a principios de 1900. Crehan hizo su debut en Broadway

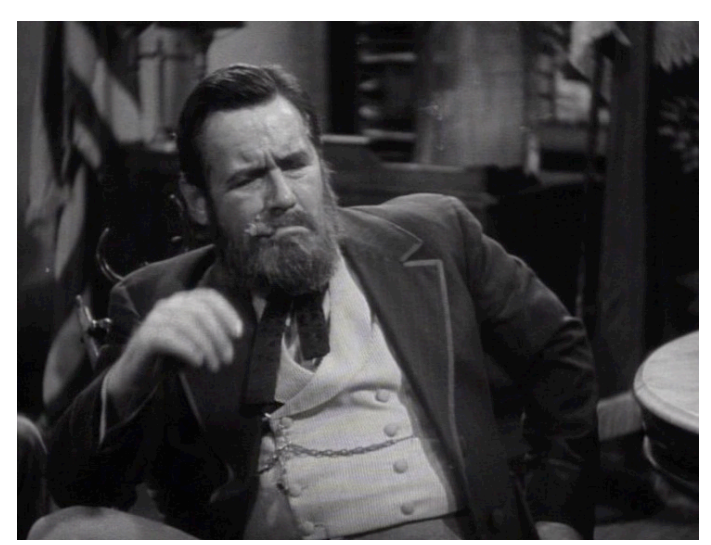
en 1914, sin mostrar prácticamente interés alguno en las películas hasta la llegada del cine sonoro. Robusto y de aspecto severo, el actor se encasilló de inmediato en figuras marcadas por la autoridad, como jefes de policía, alcaldes de pueblo y directores de periódicos. Debido a su baja estatura, su voz ronca, su peculiar forma de caminar y que solía portar una barba que le proporcionaba un notable parecido con Ulysses S. Grant, el actor logró interpretarlo en varios filmes, incluyendo Union Pacific (Cecil B. De Mille, 1939, que analizaremos a continuación) y, sobre todo, en Murieron con las botas puestas (Raoul Walsh, 1941).

Entre sus 340 créditos se encuentran clásicos como Sucedió una noche (Frank Capra, 1934), El sueño eterno (Howard Hawks, 1946), y Monsieur Verdoux (Charles Chaplin, 1947). En todas las ocasiones en que Crehan encarnó a Grant apenas necesitó caracterización, pues no sólo su rostro, sino todo su físico, hacía recordar a la figura del mandatario. El actor tuvo además la suerte de trabajar con grandes directores que situaron sus filmes entre los más destacados de la historia; por ello, a pesar de su corta comparecencia en 
los mismos, siempre se le recordará como un pilar fundamental en la exposición mitificada del presidente.

Con todo, el Ulysses Grant de Joseph Crehan, como el del resto de los actores que lo encarnaron, se configura, como vamos a ver, como un personaje cuyas apariciones en pantalla gravitan en torno a dos ejes fundamentales: su brevedad presencial (en torno a unos dos minutos como máximo), y lo decisivo de sus intervenciones, a veces cincelando incluso la esencia narrativa del filme.

\subsubsection{La película}

El primer acercamiento importante a la figura del general Grant es, pues, este filme de 1939, en el que DeMille nos sitúa temporalmente durante la campaña presidencial del general. Partiendo de la base histórica de que "pocas veces una empresa humana ha afrontado más dificultades y peligrosos obstáculos naturales que la asumida por los topógrafos, los ingenieros y las brigadas de trabajo del ferrocarril transcontinental estadounidense" (Doval, 2009, p. 299), la película refleja una visita de Grant a las obras del ferrocarril Unión Pacific, en la que, en una secuencia concreta, conversan el general Dodge (Francis McDonalds), Oakes Ames (Willard Robertson), y el aspirante a la presidencia de los EEUU sobre cómo cumplir los plazos para que el tren llegue a Promontory, el final de su trayecto. En la conversación también se encuentra Asa M. Barrows (Henry Kolker) que ha intentado por todos los medios retrasar las obras, y el futuro presidente escucha con atención las opiniones contrapuestas de los presentes. Ames ha obtenido el permiso de Lincoln para construir el ferrocarril. Hablan del futuro del país con una perspectiva histórica digna de elogio. El futuro presidente sigue las pautas marcadas por Abraham Lincoln, promotor del proyecto, de modo que al final las dos líneas principales de ferrocarril (la otra era Central Pacific) terminaron uniéndose en Promontory Summit (Utah), a 53 kilómetros al oeste de Ogden, constituyendo, a partir del 10 de mayo de 1869, la primera línea transcontinental de América del Norte. Lo increíble es que el final de esta magna empresa se fragua en una conversación que no dura ni dos 
minutos, y en la que el espectador adquiere además una visión global y casi ideal lo que supuso este proyecto.

- Sr. Ames (A): Tales retrasos significan un gran desastre, General Grant. Nuestro crédito está llegando a su límite. Hay elementos que, fuera de toda ley y de toda razón, entorpecen los trabajos que se realizan aquí, y en el terminal es una monstruosa conspiración la que persigue la ruina del ferrocarri,l y ahora el señor Barrows propone una nueva desviación al oeste de Laramie.

- Barrows (B): Eminentes ingenieros me informan de que la presente ruta es impracticable.

- General Dodge (GD): Yo en su lugar me hubiera dejado aconsejar por un búfalo

- B: ¿Un bufalo? No bromee, general.

- GD: El ferrocarril se está construyendo sobre un rastro de búfalos. Estos animales son viajeros prácticos, señor Barrows, y nunca han desviado su ruta por razones financieras

- A: Si lo hacemos nosotros nos ganará la partida el Central.

- GD: Mi única inquietud, General Grant, es tener que alargar nuestra linea. El señor Barrows solicita 99 millas adicionales. Si así se ordena, presento mi dimisión como ingeniero jefe.

- Grant (G): El Gobierno espera que la compañía termine el ferrocarril con arreglo a lo contratado. Igualmente espera que el general Dodge conserve su autoridad. Señor Ames, ¿cuánto dinero se necesita para pagar inmediatamente facturas y jornales?

- A: Lo menos un millón de dólares.

- G (dirigiéndose a B): Usted, que tan profundo interés parece tener por el ferrocarril, señor Barrows, ¿porque no anticipa al señor Ames lo que pide?

- B: ¿Un millón de dólares?

- G (con energía): Sí... Para la Unión Pacifico.

- B (acorralado): Considero un privilegio servir al ferrocarril y al futuro presidente de los EEUU. La primera remesa de fondos será enviada antes de terminar la semana. General... Caballeros...

- A y GD: Gracias, general, muchísimas gracias.

- GD: Cuesta muchísimo dinero poner vías en esas montañas.

Por otro lado, y al igual que en Murieron con las botas puestas y Rio de plata, esta es la única secuencia en la que aparece el General Ulysses Grant, y en las tres lo hace en el momento de mayor inflexión del filme. Basta un breve ejercicio de inventario para recordar que, en el primero de ellos, el General Custer visita al que ya es presidente de los EEUU y es éste quien le otorga el permiso que todos le niegan para incorporarse al Séptimo de Caballería en su lucha contra los nativos. En Rio de plata, es también su presencia la que cambiará la economía del pueblo, y lo que hará que el 
protagonista acumule una gran riqueza que será el principio de su fin. Por último, en Union Pacific, Grant es el elemento impulsor para que, a pesar de los problemas de la línea, ésta cumpla con su objetivo, dentro de una trama fundamental que terminará con el encuentro de los dos gigantes del ferrocarril en Promontory. En definitiva, una presencia mínima pero influyente, y recordada en la medida en que también coadyuvan la disposición de las secuencias en el guión y, sin duda, la imponente presencia de Joseph Crehan.

\subsection{Murieron con las botas puestas: General Grant vs. General Custer}

Murieron con las botas puestas (Raoul Walsh, 1941) es, en justicia, una película sobre el General Custer. Si bien (Everson, 1992) manifiesta que Walsh actuó "convirtiendo la película casi en una pieza relacionada con su película de 1939, The Roaring 20's" (p. 213), amén de “en un pintoresco desfile que comenzaba con los sucesos que condujeron a la guerra civil, la guerra misma y sus consecuencias, y la apertura del Oeste, y las, cada vez mayores, batallas con los indios" (p. 215), la cinta no descuida, pese a todo ello, la imagen mitificada del citado personaje (encarnado por Errol Flynn), incidiendo en un doble retrato que bascula entre la extravagancia y una valentía que apenas se distingue de la temeridad. Custer -a medida de los personajes que encarnaba el propio Flynn- es arrogante e imprudente pero a la vez elegante y romántico. Según su descripción histórica, Custer era muy elegante y alto, y sin duda un hombre muy apuesto para su época. Tenía un poblado bigote que acertadamente fue eliminado en el filme, aunque, si se trata de advertir las diferencias entre el Custer de la ficción y el real que deben interesarnos, cabe resaltar (en línea con nuestras argumentaciones sobre Grant), que el que aparece en la película bebía con moderación, cuando el auténtico era un gran bebedor que solo abandonó el hábito cuando se adentró en la frontera (justo lo contrario de lo que hace en el filme). El auténtico general Custer era muy elegante y presumido, y también lo era el fílmico, rozando en este caso lo hiperbólico. En cuanto a las similitudes entre 
realidad y ficción, si bien la película puede catalogarse como un -espléndidofilme de aventuras con aspectos folletinescos, no es menos cierto que el honor se debe al retrato de Flynn de un Custer terco, y decidido a alcanzar la gloria y a cumplir su destino, cuando lo realmente cierto fue su muerte violenta y la desaparición de su Séptimo de Caballería en la masacre de Little Big Horn.

En el correlato histórico de la secuencia que a continuación vamos a exponer, Ulysses Grant no había aún entrado en combate, y todavía no había destacado por méritos militares. Sin embargo, en este diálogo, queda claro el rechazo de algunos oficiales a su figura recordando el episodio real que, en su

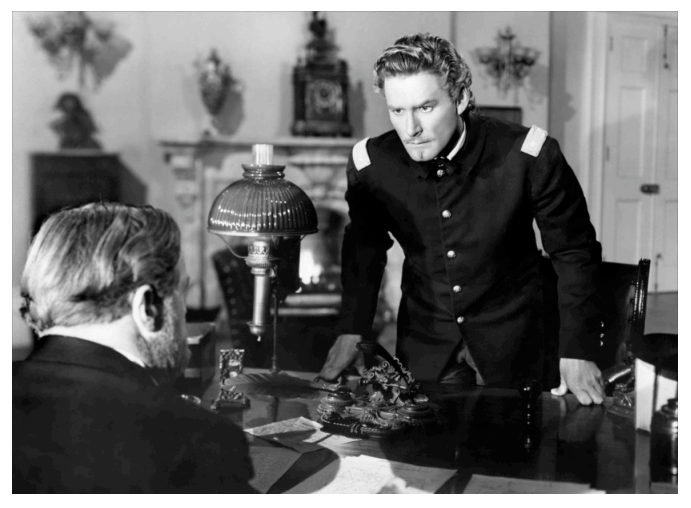
juventud, le hizo granjearse el sambenito de peor cadete que había pasado jamás por West Point. En este instante de la cinta, Custer es víctima de una novatada, al llegar a la Academia, y reacciona violentamente contra el responsable de la misma. En consecuencia, es arrestado y puesto a disposición del Coronel Philip H. Sheridan (John Litel) para certificar su expulsión.

- Sheridan (S): Señor Custer, se le acusa de un delito grave. ¿No sabe que pegar a un superior es una falta grave, en el código de justicia militar, que se puede castigar con la muerte? ¿Por qué pegó al señor Shart?

- Custer (C): No puedo decírselo, señor. Un asunto personal.

- S: Dentro del cuartel no hay asuntos personales. ¿Tiene algo más que decir?

- C: No, señor.

- S: No tengo más remedio que expulsarle a usted de la Academia.

- C: ¿Expulsado? No creí que me hicieran eso por pelear.

- Comandante Instructor (CI): Bueno, pues ya lo sabe.

- S: (Sorprendido gratamente por la sinceridad del cadete) ¿Cuál es su compañía, Señor Custer?

- C: ¿Compañía?

- CI: Si, compañía. ¿No lo sabe? El impreso que firmó en la oficina.

- C: ¿Qué impreso? No he firmado ningún impreso y no he estado en ninguna oficina. 
- S: ¿No ha firmado entonces su hoja de alistamiento?

- C: No, señor.

- S: En tal caso, no podemos expulsarle del ejército, porque no ha ingresado en él. Ha tenido usted suerte. Que esto le sirva de lección. Llévelo al ayudante, Sargento.

- Sargento: iA la orden, señor! iMedia vuelta, ar! (Custer intenta dar las gracias). iMedia vuelta, ar!

- C: Gracias de todas formas, señor. (Sale del despacho acompañado del Sargento Mayor.)

- S: Mire, Dave, me alegro de que haya resultado. Hay algo en ese tipo que me agrada.

- CI: Ah, ¿sí?, pues no sé que puede ser. Si quiere mi opinión, le diré que hubiese sido el peor cadete de West Point después de Ulysses Grant.

Apenas un par de secuencias posteriores de la relatada aquí, West Point ve como gran parte de sus cadetes la abandonan al sentir de cerca la Guerra de Secesión. Con la llegada de Lincoln, la guerra estalla y la plana mayor de la Academia se plantea seleccionar a algunos cadetes para que formen parte de la oficialidad. Cuando surge el nombre de Custer, el diálogo que se establece es el siguiente:

- Sheridan (S): No comparto la idea de graduar a los cadetes. A pesar de la urgencia, tener un oficial a medias es peor que no tener ninguno. Pero no puedo convencer al Ministerio de la Guerra.

- Oficial 1 (O1): Al menos podemos elegir nosotros. ¿Quién es el primero alfabéticamente?

- Oficial 2 (O2): El cadete Percival Anderson.

- S: ¿Anderson? Ese nombre no me dice nada.

- Comandante Instructor (CI): No es de los que destacan. Su historial es impecable.

- Oficial 3 (O3): Podría ser que buscase no crearse problemas.

- S: Anderson nos vendrá mejor dentro de un año. Tendrá que aceptar responsabilidades y tomar decisiones.

- O2: Lo sé, señor, pero...

- S: Siguiente.

- O2: George Armstrong Custer.

- S: De éste no se puede decir que no destaque...

- CI: No, señor, no se puede decir. No tiene respeto a la disciplina, a la organización, a la táctica. Y en cuanto a su historial... Custer tiene las notas más bajas y las faltas más graves que haya tenido ningún cadete. Incluido Ulysses S. Grant. 
En la secuencia que analizaremos a continuación, y a pesar de que siempre, en la mayoría de los filmes donde aparece la figura de Grant, surgen comentarios sobre su expulsión del ejército, sus mediocres notas, o la corrupción generalizada en su segundo mandato, su figura como presidente es casi siempre intachable, o al menos aparece redimida de algún modo. En esta ocasión, además, el guión le concede una humanidad incuestionable: la conversación entre Custer y Grant que nos es relatada carece, en definitiva, del mínimo asidero realista.

Como vemos, siempre que se habla de Ulysses Grant en tercera persona los comentarios son deleznables, pero no es menos cierto que el contexto se reserva en todo caso visos muy marcados de apariencia. Analizando el guión de este filme, comprobamos que los comentarios se transforman en positivos ateniéndonos a dos circunstancias. Primero, el modo despreciativo con que se trata a Custer, comparándolo al que algunos años después sería Presidente de los Estados Unidos. Segundo, el hecho de que, a pesar de estas críticas, ambos personajes, en la visión global del filme, se ven ensalzados como héroes, $\mathrm{y}$, más importante aún, como hombres honestos y justos. Para confirmar este hecho, solo tenemos que transcribir el único diálogo de toda la película entre Ulysses Grant y George Custer. Custer le pide ayuda al General Sheridan porque desea volver a su regimiento y coger el mando. Sabe que se dirige a una muerte segura, pero aun así no entra en sus intenciones abandonar a sus hombres. Sheridan considera que Custer trata de suicidarse con su regimiento pero, ante su insistente súplica, le contesta que la única persona que puede concederle el mando es el Presidente Ulysses S. Grant, y que éste está muy molesto por el próximo juicio contra él, hasta el punto de no querer tener noticias suyas. Aun así, el general se presenta en su despacho y, ante la negativa a ser recibido por el presidente, aparta a su secretario y entra sin permiso. El diálogo es en un principio bastante tenso:

- Grant (G): Le recuerdo que soy el Presidente de los Estados Unidos de América.

- Custer (C): No he venido a ver al Presidente de los Estados Unidos, sino a un militar.

- G: Bastantes trastornos ha ocasionado ya por meterse en la política.

- C: Quiero que se me reintegre a mi regimiento. 
- G: Tiene usted que comparecer ante un consejo de guerra.

- C: iAl infierno el consejo de guerra! Quiero que se me reintegre a mi regimiento.

- G: Por lo menos dígame por qué he de hacerlo.

- C: Le diré por qué. Porque usted sabe lo que siente un hombre cuando le hunden, cuando le dejan atrás y su regimiento va hacia el combate. Usted sabe lo que se siente porque lo ha experimentado sobre sí mismo.

- G (se levanta y apura su puro. Son treinta y cinco segundos interminables en el que sólo exclama un "iFuera!" en el momento en que entra el secretario, con dos agentes de seguridad, alertados por la actitud de Custer. Finalmente, el presidente se sienta, suelta el puro y exclama): De acuerdo.

La mitificación del presidente se hace acompañar, paralelamente, en este caso, por la de Custer. Ambas vidas parecen discurrir por sendas muy parecidas: la expulsión del ejército, las críticas de sus superiores, sus aficiones por la bebida y las pendencias... Todo lo que se dice del general puede ser comparable a lo dicho sobre el presidente, y sus cuitas parecen igualmente tenderse puentes vitales. Por ejemplo, cuando Elizabeth Bacon (Olivia de Haviland), la mujer de Custer, pide en un momento un destino para su marido, toda vez que la inactividad le hace incidir (como a Grant) en el vicio del alcohol.

\subsection{Rio de plata}

Dirigido por Raoul Walsh en 1948, este filme cuenta la historia de "Mike" McComb (Errol Flynn) un capitán del ejército que en plena Guerra Civil, y acompañado de su fiel amigo "Pistol" Porter (Tom D'Andrea), quemaron un millón de dólares para evitar que cayeran en manos de los sudistas, por lo que ambos resultan expulsados del ejército. El antiguo capitán marcha a Nevada donde, de forma poco lícita, se hace con una fortuna especulando con las minas de plata, la banca y el juego. Georgia (Ann Sheridan), la mujer que ama, se ha casado, y McComb no duda en emplear todas sus mañas para evitar que el matrimonio continúe.

En este contexto, llega a Silver City el presidente Ulysses Grant (Crehan), al que podemos contemplar igual que en Murieron con las botas puestas en una sola secuencia. En este caso, a través de lo que en ella se dice de él, advertimos su preocupación por el desarrollo económico de los EEUU. Como 
cabe esperar, igualmente, al enterarse los hombres poderosos de Silver City de su llegada, lo primero que indican es que tienen su marca preferida de whisky, no en un sentido negativo, sino en una atmósfera de coloquial, que a la postre queda rubricada por la luminosa expresividad del actor frente a la cámara. En otro instante, vemos a Mike dirigirse a los hombres poderosos de Silver City, mientras el presidente baila con Georgia, cuyo marido es Stanley Moore (Bruce Bennett), honrado propietario de una mina de plata. Mike alega ante los presentes que tiene un mensaje del presidente, pero cede la palabra a su buen amigo John Plato Beck (Thomas Mitchell).

- Mike (M) (dirigiéndose a John): Plato, tú estabas allí. Cuéntales, cuéntales.

- John (J): Bien, como saben, una nación de categoría es una nación con créditos internacionales. Inglaterra tiene su imperio; minas de de diamantes en Kimberly, de plata en la India, de oro en el Rall y de estaño en Malasia. Rusia tiene las estepas de Siberia, ricas en cientos y cientos de recursos

- Buck Chevigee (Monte Blue): ¿Y qué me dice del oro de California, Oregón o Colorado?

- J: Exacto, los del 49 nos dejaron el oro, pero eso no es suficiente, no. Se acabaron las minas de oro. ¿Saben qué es lo que hace falta para que este país sea el mayor acreedor de todas las naciones?

- M: Plata, en pocas palabras señores. Esto es lo que ha dicho el presidente. Tienen que producir más plata, aunque deban trabajar las 24 horas del día, extrayendo más, enviando más. Han de producir más plata. Hasta ahora, naturalmente, cada uno ha estado sacando plata para ver lo que se podía meter en el bolsillo. Bien, pero esto ha cambiado. Silver Cyty tiene ya más importancia que nosotros. De lo que aquí hagamos, caballeros, depende el futuro de América. Ya me parece ver en el territorio que nos rodea, los cimientos de un gran imperio. Y, si somos listos, empezará por los que estamos aquí.

- Stanley Moore: El territorio es rico en plata. Buscaremos nuevos yacimientos, redoblaremos nuestros esfuerzos.

- M: Ya sabía yo que estaría de acuerdo conmigo. Perdón, conmigo y con el presidente. Vengan mañana por el banco y concretaremos los detalles.

En definitiva, se habla del presidente como de un visionario que sabe que las minas de oro están agotadas y la plata es la alternativa. En el filme, además, la codicia de "Mike" no termina de ensombrecer las intenciones de progreso del presidente Ulysses.

Por otro lado, la vertiente lúdica que apuntalábamos con anterioridad queda patente con la conversación que concluye la secuencia, en la que "Pistol" 
Porter charla con el presidente sobre el millón de dólares y la expulsión del ejército:

- Porter (P) (mientras el presidente parece mirarle incrédulo con un vaso de whisky en su mano): ¿Qué otra cosa podíamos hacer? Quemar el millón de dólares, qué hoguera; yo tenía treinta y seis mil dólares de ceniza en mi gorra, y por eso me echaron del ejército...Valiente gratitud... ¿A usted también le echaron una vez del ejército, no?

- Ulysses Grant (mirándole con curiosidad y con la mirada algo perdida): No...Dos.

- P: Y sin embargo, ahora tiene un buen empleo (el presidente vuelve a mirarlo con incredulidad).

La expulsión de Ulysses Grant del ejército, vista en el contexto de este filme, no haría más que acrecentar su leyenda, toda vez que muestra al hombre con un pasado superado y un carácter visionario, que al tiempo comparte los mismos problemas que los protagonistas principales. Incluso sus problemas con el alcohol no pueden dejar de apreciarse con simpatía en esta escena con Porter.

\subsection{Tambores de guerra}

La siguiente propuesta, firmada en 1954 por Delmer Daves, comienza con la huida de un grupo de indios de una reserva. Estamos en 1870, unos años después de la Guerra de Secesión (1861-1865), en el marco de las guerras apaches, cuando los indios eran obligados a abandonar sus tierras e instalarse en las reservas. El presidente de los Estados Unidos, Ulysses Grant (Hayden Rorke), confía a Johnny McKay (Alan Ladd) la misión de llevar la paz al sur de Oregón. Esta vez, McKay tendrá que lidiar con el capitán Jack (Charles Bronson), el líder de unos renegados que han sembrado de terror la región matando a todos los colonos que se cruzaban en su camino. Estamos en un momento de la Historia en que el ferrocarril ha cerrado una parte importante de la frontera. Apenas un año antes, recordemos, el Central y el Unión Pacific se habían encontrado ya en la ciudad de Promontory.

La primera imagen del filme es la de un pergamino sobre el que se puede leer que la historia que se va a contar es real, y que se han añadido algunos personajes de ficción en favor de una mejor dramatización. 
El protagonista, Johnny MacKay, a quien da vida Alan Ladd, se encuentra en las afueras de la Casa Blanca, y habla con un soldado, mutilado de una pierna, que se halla de guardia en la entrada observando cómo juegan unos niños negros. Sin dar importancia a su puesto, el soldado le indica a Johnny que puede entrar como si estuviera en su casa, y que pregunte a cualquier general por el presidente, dado que todo el mundo le conoce. Al entrar ve a varios oficiales que parecen esperar; Johnny entrega una carta al oficial, éste le indica que se siente un momento y que le dirá al presidente que se encuentra en la entrada. Johnny obedece, se sienta junto a un hombre (Edgar Stehli) y mantienen la siguiente conversación:

- Extraño (E) (le mira de arriba abajo, lo que parece incomodar a Johnny): ¿Va a matar al presidente?

- Johnny (J): ¿Se ha vuelto loco?

- E: No, que va; es solo curiosidad. Pistola, cuchillo... Da toda la impresión.

- J: No señor. (Con curiosidad) ¿Le conoce? (El extraño asiente y Johnny se le acerca intrigado). ¿Cómo es?

- E: Un carácter endemoniado. Fuma como una chimenea y un bebedor empedernido. Creo que no es lugar para él esta casa.

- J (enojado): ¿Es usted un misionero?

- E: ¿Yo? (se ríe).

- J: Parece que no le gusta el presidente.

- E (rotundo): Se equivoca, muchacho. Soy su padre (en ese instante se abren las puertas y aparece el presidente Ulysses Grant (Saludando al extraño). Hola, papá.

- Jesse Root Grant (JRG): Hola, hijo.

- Ulysses Grant (UG): ¿Johnny MacKay?

- J: Si, señor.

- UG: Ha venido muy rápido.

- J: En tren, señor, solo he viajado diez días

- UG (dirigiéndose a su padre): ¿Por qué estás aquí fuera, papá? ¿Por qué no vinisteis a cenar?

- JRG: No me gusta oír al doctor Thomas hablar de los pobres indios.

- UG: Todo lo que quiere conseguir el doctor Thomas es la paz con los indios, igual que yo. (Dirigiéndose a Johnny) Vamos dentro, le presentaré al doctor.

- JRG (Se levanta acompañando al presidente y, dirigiéndose a Johnny): En ese caso no se aleje del cuchillo.

- Thomas (T) (Richard Gaines): En muchas partes de California han solicitado que vayan a matar a los indios. A matar indios estén donde estén. 
- UG (en tono de broma): Señoras, a mi lado se encuentra el mejor cazador de indios del país. Señora Grant, le presento a Johnny MacKay

- Señora Grant (Peggy Converse): ¿Cómo está, señor MacKay? Esa es nuestra hija Nellie.

- Nelly (N) (Carol Nugent): ¿Realmente ha visto a los pieles rojas cortar cabelleras?

- J: No cortan cabelleras, señorita. Cortan cabezas.

- UG: La señorita Nancy Meek.

- N (Audrey Dalton): Puedo entender cómo se siente la señorita Nellie. Es tan fuerte y salvaje como cualquier chica del Este podría desear.

- J: Gracias señora. No me gustaría decepcionarlas.

- UG: Sé cómo se siente. He decepcionado a miles de personas por no tener aspecto de general. Esta chica del Este va a convertirse en una del Oeste y quizás tenga que protegerla por algún tiempo. Doctor Thomas, antes estaba maldiciendo a los cazadores de indios. Le presento al mejor.

- T (mientras Johnny se le acerca con la mano extendida): ¿Tiene sangre en las manos?

- Señora Grant (SG) (viendo la tensión creada y cómo Johnny se ha quedado paralizado sin saber qué hacer): ¿Quiere tomar un café, señor MacKay?

- J: No, señora. Gracias.

- UG: ¿Quiere sentarse, MacKay?

- J: No, gracias.

- UG (todos se sientan menos Johnny): Bien, MacKay, infórmeme de los indios Modocs y de su líder, el capitán Jack.

- J: La situación está controlada, señor, pero el capitán Jack no quiere rendirse.

- UG: ¿Qué tipo de hombre es?

- J: Muchos dicen que tiene sangre blanca. Por sus ojos claros, pero sobre todo por su mala sangre.

- UG: Me han dicho que la única solución es hacer regresar al capitán Jack a la reserva con todos los demás Modocs. Ha cumplido el tratado.

- J: Es una posibilidad.

- T: ¿Qué hay del tratado Modoc?

- J: El capitán Jack dice que nunca lo ha leído. Pero miente, señor.

- T: ¿Le diría mentiroso a la cara?

- J: Ya lo hice (en ese momento, el padre del presidente se ríe, y el presidente le mira con severidad). Pero sé que hace buenos tratos con los hombres blancos.

- J: Claro, les consigue esposas indias. Tiene muchas cartas que le alaban. Y cuando tiene problemas con la justicia...

- T: Eso no afecta a la justicia.

- J: No es cierto, pero también tiene la justicia de la paz. Una esposa india. 
- N: ¿Le ofreció a usted una esposa india?

- J: Si, señora.

- N: ¿Está casado con una?

- J: No, señora.

- N: ¿Siente escrúpulos por ello?

- J: ¿Cómo ha dicho?

- N: Si se opone al matrimonio mixto.

- J: No, señora. Yo espero casarme algún día.

- N: Quiero decir que si el casarse con una india es aceptable en esas tierras.

- J: Pues sí, señora, no hay muchas mujeres blancas.

- Señora Grant: Nellie, creo que ya es hora de acostarse.

- Nelly: Pero si yo no digo nada, mamá. Solo escucho.

- SG: Ya veo.

- UG: Está aprendiendo historia de primera mano, Julia. ¿Cree usted que el capitán Jack estará dispuesto a llegar a la reserva de forma pacífica?

- J: Bien, creo que ya lo intentamos, señor. Y fracasó.

- UG: Ya me han dicho que los colonos solo quieren la paz de los rifles.

- T: Ahora parece que es más duro tratar con los colonos que con los indios.

- J: Cuando matan a los tuyos, te vengas.

- T: ¿Ha matado indios?

- J: Bastantes.

- SG: Ahora sí que te acuestas, Nellie. Si no, tendrás pesadillas.

- N: Me gustan las pesadillas, me gusta tener miedo.

- UG: Vete a la cama, Nellie.

- N (se despide de todos muy ceremoniosamente; por último, se dirige a su abuelo): Buenas noches, abuelo.

- T: ¿Está arrepentido?

- J: No, señor.

- T: No debería...

- J: Nunca he matado sin motivo. Mi trabajo es el de proteger a los blancos. Y si alguien dispara a mi gente, yo también disparo.

- JRG: iBravo, muchacho! iEste tipo es formidable!

- T: Tengo gran curiosidad por saber de qué clase de familia viene.

- J: Pioneros.

- SG: ¿Aprueban su trabajo?

- J: No es necesario.

- T: No me extraña.

- N: ¿Y dónde están ahora? 
- J: Enterrados en Bloody Point.

- SG (sorprendida y alarmada): ¿Bloody Point? Allí hubo una matanza.

- J: Si, señora.

- N: ¿'Toda su familia?

- J: A mi padre y a mi madre... y al pequeño, les quitaron la cabellera. A mis dos hermanas de doce y catorce años no las mataron enseguida. No duraron mucho. Las indias se pusieron celosas y las acuchillaron. Mi familia quizás no hubiera aprobado que me hiciese cazador de indios, pero no pude preguntárselo.

- UG: Supongo que se preguntará por qué le he llamado. Fui educado como un sol dado. Sé que un cazador sabe como nadie lo que es la paz. Quiero que se dejen los rifles y que se pacifiquen esas tierras.

- J: ¿Hacer volver al capitán Jack a la reserva?

- UG: Es la única forma de conseguir la paz, ¿̇no?

- J: ¿ंSin armas?

- UG: Si es posible... ¿Lo intentará?

- J (lo piensa brevemente y sonríe): Bien. No he recorrido 3000 millas para decir que no a mi presidente.

- UG: ¿Entonces lo hará?

- J: Haré todo lo posible, señor.

- UG: Es todo lo que le pido. (Le extiende la mano). Gracias y le deseo mucha suerte en esa aventura.

Muy importante resulta este comienzo, que de nuevo respeta las premisas que, sobre el presidente Grant, parece que estableció el cine de Hollywood desde sus comienzos hasta prácticamente nuestros días. Ahora es el padre de Ulysses el encargado de mostrarnos sus grandes defectos -aunque una vez más con la aureola propia de los héroes- como un presidente pendenciero, fumador y bebedor empedernido del que se sugiere que ni siquiera debería vivir en la Casa Blanca. De la misma forma que a algunos personajes enteramente de ficción se les mitifica haciendo que hablen de ellos en tercera persona, Ulysses Grant siempre es engrandecido por los comentarios de un tercero que habla de sus defectos como si fueran virtudes.

Una segunda postura es la del guerrero y hombre de estado que presenta a Johnny MacKay como un cazador de indios y como hombre de guerra. Ulysses se define a sí mismo como hombre de guerra, y dice que esto le convierte en la persona idónea para buscar la paz. Si en Flecha rota (1950), el propio Daves preludiaba toda una serie de películas que mostraban una 
visión de los indios alejada de los estereotipos del Hollywood clásico, en Tambores de Guerra todavía nos encontramos con la concepción habitual de los nativos americanos, y de lo que trata el presidente es de hacer llegar la paz a las tierras donde se dirige MacKay. En ningún momento, además, se muestra comprensivo con la actitud del sanguinario capitán Jack, quien se ve obligado a abandonar las tierras en las que siempre vivió para ir a una reserva.

Gracias al diálogo descrito puede colegirse, también, cómo el ferrocarril, impulsado en su trayecto final por el presidente Grant, logró que las distancias de meses en carretas para ir del Este al Oeste de los Estados Unidos se redujeran a poco más de una semana.

\subsection{Misión de Audaces}

John Ford siempre había albergado el sueño de filmar una biografía de Ulysses Grant. Lo recuerda (McBride, 2004, p. 672), al afirmar que "Ford había pensado contar al menos parcialmente la historia de Grant como parte de la serie" - refiriéndose a la televisiva Wagon Train, para la que terminaría realizando un episodio alegórico en 1960-, volviendo sobre la figura del presidente tan solo un año después de haber firmado una de las grandes películas sobre la Caballería de los Estados Unidos de la mano del más ilustre representante del género del western, John Wayne, quien para la ocasión se hizo acompañar por William Holden.

La cinta está basada en un episodio real. En la primavera de 1863, y dentro de la campaña de Vicksburg, 1.700 jinetes al mando del coronel. Benjamin $\mathrm{H}$. Grierson cabalgaron unos 1.000 kilómetros a través de territorio enemigo. Entraron por el sur de Tennessee, atravesaron el estado de Mississippi, y llegaron hasta la base de la Unión en Baton-Rouge (Louisiana). Durante su recorrido, destruyeron todas aquellas instalaciones que podían ser útiles a las fuerzas del Sur (vías de tren, almacenes, puentes o campos de algodón). Al término de la campaña solo habían sufrido 3 muertos, 7 heridos, 9 desaparecidos y 5 hombres enfermos que tuvieron que quedar atrás. 
Esta estrategia provocó que el general confederado Pemberton utilizara toda una división para proteger el ferrocarril. Vicksburg se abastecía gracias a este nudo ferroviario, y la maniobra facilitó la entrada del general Ulysses Grant, cuyo pronto asedio a Vicksburg provocó su caída el 4 de julio de 1863.

En la película, John Wayne interpreta al coronel John Marlowe, el típico soldado duro y profesional. Por su parte, Holden interpreta al antagonista, en este caso un médico que se debate constantemente entre su deber de luchar como soldado y el de salvar vidas mediante la profesión que domina. Completa también el reparto el retrato clásico de la señorita sureña que encarna Constance Towers, y que aquí es obligada a acompañar al destacamento porque ha escuchado el plan de ataque.

El filme se arroga una importante cuota de realismo al plasmar tanto la proeza del internamiento en territorio enemigo como la carga de los soldados confederados en el pueblo donde les esperan agazapados los Unionistas, aunque especula con la participación de los cadetes sureños (apenas unos niños), que al menos en este episodio de la Guerra Civil no estuvieron presentes. Por otro lado, y para concluir el inciso, la utilización de remedios indios por parte del médico, así como el hecho de que hirviera los instrumentos de sus operaciones, no parece confirmarse históricamente, ya que el uso de la penicilina y la práctica de hervir los instrumentos quirúrgicos es posterior a la época, y se hizo primeramente en Europa.

Conforme a la línea argumental que hemos abierto en torno a que en la mayoría de las películas que narran hechos reales o ficticios, y que sucedieron en la etapa en que Ulysses Grant aparecía como general o como presidente, su presencia en pantalla se reduce en esta ocasión a 2 minutos y 24 segundos. De igual forma, esta brevedad es directamente proporcional al engrandecimiento del personaje como líder y visionario del futuro de país, algo que afecta a su construcción como personaje, incluido el plano físico: su poblada barba, el gabán azul sobre el uniforme y su prominente puro se erigen siempre en señas particulares de identidad. En Misión de audaces, Grant comparece al principio, durante una reunión que mantienen Marlowe (John Wayne) y tres generales: William T. Sherman (Richard H. Cutting), 
Ulysses S. Grant (Stan Jones) y Steve Hurlburt (William Forrest). Todos se reúnen para hablar de la misión, $\mathrm{y}$, al anunciarse la llegada de Hurburt y del coronel John Marlowe, es Grant quien les invita a entrar, con su sempiterna copa de brandy en la mano.

- Grant (G): Steve, adelante

- Hurlburt (H): Hola, Sam. Coronel Marlowe...

- Marlowe (M): Señor...

- Sherman (S) (saluda a Hurburt): ¿Qué tal?

- H (presentando): El gran Sherman, coronel Marlowe.

- G: Marlowe, tenía deseos de conocerle.

- M: Gracias, general.

- S: Siéntense, siéntense. ¿Es su primera visita a Vicksburg, coronel Marlowe?

- M: Sí, señor.

- G: Nosotros llevamos aquí diez meses y estamos hartos. Coronel, debo decirle que la guerra, por nuestra parte, no ha ido muy bien.

- S: Ni en Washington, ni en los periódicos ni en campos de batalla.

- G: en una palabra, con menos hombres y menos recursos, el Sur nos tiene metidos en un puño. Si pudiéramos tomar Vicksburg cambiaría el panorama, pero hay que tomarla este verano.

- S: O quedarnos aquí otro año, lo que nos costaría cien mil hombres más y, quizás, perder la guerra.

- G: Tenemos que atacar su fuente principal de aprovisionamiento. Es nuestra pesadilla: la estación de Newton.

- H (dirigiéndose a Grant): Sam, Marlowe ha estudiado muy - detenidamente los detalles de ese plan.

- G: Dígalos.

- M: Si yo volviese enseguida a La Grance, podríamos salir el jueves (se levanta y se dirige a un mapa para señalar la ruta a seguir).

- G: Bien, ¿qué fuerzas llevaría?

- M: Mi primera de Illinois, la primera de Michigan de Secort y la segunda de Iowa de Blanning. Formaríamos una pequeña brigada, cruzaríamos La Grance y atravesaría Ripley, New Albany, Houston (Marlowe observa que Grant no mira el mapa). ¿No le parece bien, señor?

- Grant: Conozco el terreno, coronel. Siga.

- M: Bueno, lo más importante es no combatir hasta llegar a la estación de Newton.

- S: ¿Cuánta línea férrea podría destruir?

- M: Toda la que encuentre a mi paso; al menos la suficiente para que tarden un par de meses en reconstruirla. De otro modo, solo conseguiríamos lo que hasta ahora. 
- G: Está bien, adelante. Destruyes raíles, traviesas, edificios, puentes y todo lo que crea que pueda entorpecerles.

- H: Sam, aunque consiguiera llegar a Newton, se encontraría a más de trescientas millas en territorio de la Confederación.

- G: ¿Ha pensado en la vuelta?

- M: ¿Y usted, señor?

- G: Bueno, yo soy el que pregunta, pero no me gustaría verme metido en la cárcel de Anderson. Es una cloaca.

- M: Tampoco me gustaría a mi señor.

La dureza de las palabras de Grant rivaliza con su preocupación sobre el futuro de la compañía del coronel Marlowe. La iluminación, su posición sentado en la penumbra, la forma de incorporarse para encender su desgastado puro. Toda su imagen es el reflejo de su propia construcción mítica, a la que coadyuva el añadido de unos diálogos escuetos e intensos donde los sentidos del riesgo, el deber y la honestidad se alternan para exhibir la versión más carismática del personaje histórico. Como curiosidad, por cierto, en este filme no se hace referencia a su alcoholismo, aunque sí vemos al grupo de oficiales envueltos en una cortina de humo y alcohol.

\subsection{La conquista del Oeste}

Hasta cuatro directores coincidieron en este filme coral de 1962: John Ford (con el segmento The Civil War), Henry Hathaway (al que debemos The Rivers, The Plains y The Outlaws), George Marshall (quien firmó The Railroad) y Richard Thorpe (no acreditado). La película cuenta la historia de la familia Prescott y sus duros inicios como inmigrantes, impelidos a adentrarse poco a poco en el salvaje oeste americano. En ella, Eve (Carroll Baker), la soñadora y romámtica hija de Zebulon Prescott (Karl Malden) se enamora perdidamente de Linus Rawlings (James Stwart), un rudo hombre de las montañas.

Durante la batalla de Shiloh, el general William Sherman (John Wayne) habla con el general Ulysses S. Grant (Harry Morgan) en un descampado mientras son observados por Zeb Rawlings (George Peppard) y un soldado rebelde. En esta ocasión, el tiempo que Grant aparece en pantalla suma dos minutos y cuarenta segundos. 
- General Sherman (GS): Pensaba situar la brigada Rousso en este valle, antes del amanecer. Es una batería bien escondida. ¿Lo aprueba?

- General Grant (GG): Sabe muy bien que apruebo cualquier decisión suya. Si esta mañana no hubiera mantenido el flanco, nos habrían cercado. Sherman, sentémonos un momento. Quiero hablarle.

- GS (dirigiéndose a un soldado): Una linterna.

- GG: Es posible que le den el mando.

- GS: ¿Por qué?

- GG: He visto los despachos de los corresponsales que han sido enviados hoy. Dicen que esta mañana fui cogido por sorpresa.

- GS: No fue usted, fui yo.

- GG: No importa; dicen también que estaba otra vez borracho.

- GS: ¿Es verdad?

- GG: No, pero no es posible luchar en el frente y en la retaguardia. Mañana dimitiré.

- GS: ¿Por lo que digan los periódicos?

- GG: Porque ya todos han perdido la confianza que tenían en mí.

- GS (alzando la voz): ¿Cree que yo anteriormente no he pasado por trances semejantes? Hace un mes decían de mí que estaba loco, y ahora dicen que soy un héroe. Pero loco o héroe, yo soy el mismo hombre. No importa lo que piense la gente, sino lo que piensa usted.

Soldado rebelde (le pregunta a Zeb): ¿Aquel es Grant?

- Zeb: Creo que sí

- Soldado rebelde: El general Grant.

- GS: Esta guerra se ganará en el oeste, y usted sabe cómo, lo ha demostrado, y creo que un hombre solo debe presentar su dimisión cuando se ha equivocado. No cuando tiene razón.

- GG: Nunca se me había ocurrido eso. Lo pensaré.

- GS: ¿Qué tiene que pensar? El ejército está mejor con usted que sin usted. Le necesita.

- GG: Quizás sí. Gracias, hay mucho que hacer antes de que empiece a amanecer, Sherman (ambos generales se incorporan, mientras el rebelde hace por disparar a Grant, pero es atacado y muerto por Zeb).

Como puede comprobarse, en esta ocasión sí se hace referencia al alcoholismo del futuro presidente, llegándose a dudar de sus posibilidades para mantener el mando debido a los rumores que en todos los ámbitos de la sociedad norteña circulan sobre su persona. Ello no quita para que los recursos utilizados en la escena resulten igualmente mitificadores, no ya respecto a la figura de Grant, sino también en lo concerniente a la de Sherman. Los halagos del primero afirmando que le ha salvado el pellejo a 
causa de su ineptitud no se ven sometidos a reproche alguno, sino au contraire: Sherman se culpa del desastre en la batalla y reconoce a Grant como el único líder capaz de llevar adelante la campaña. Una vez más, los defectos se vuelven virtudes, y prevalece la figura del estratega militar por encima de la del estadista y político.

La conversación, de hecho, hace además que Zeb contemple la guerra de otra forma, con una toma de conciencia que a la postre se manifiesta dando muerte a quien parecía que iba a ser su compañero de huida. La responsabilidad y el patriotismo se conjugan en el hecho de escuchar una conversación entre generales donde, si bien sus perfiles más humanos parecen destacar en el contexto, es su edificación mitológica lo que a todas luces prevalece.

\subsection{La leyenda de El llanero Solitario}

El llanero Solitario fue un personaje creado inicialmente para el medio radiofónico en 1933 por George Trendle, y desarrollado por el escritor Fran Striker. Su voz en las ondas correspondió a Paul Halliwell, mientras que Clayton Moore protagonizó, en la serie televisiva homónima, la mayoría de sus 221 episodios, de 23 minutos cada uno, emitidos entre 1949 y 1957. El actor John Hart interpretó el papel, entre 1951 y 1953, a lo largo de 26 episodios; Jay Silverheels fue su fiel compañero Tonto (Toro para el mercado latinoamericano). El llanero Solitario era un Ranger de Texas llamado John Reid, único superviviente del ataque de Butch Cavendish y su pandilla. Curado por Toro, su amigo indio de la infancia, Reid jura ayudar a cumplir la justicia del Oeste portando una máscara. Armado con dos revólveres que disparaban balas de plata que podían herir, pero nunca matar, cabalgaba sobre Silver (Plata), su fiel caballo. En la última temporada, Chuck Courtney interpretó a Dan Reid, el hijo del Llanero.

El éxito de la serie fue tan grande que las salas de cine conocieron dos largometrajes, más otra serie, en este caso de animación, emitida entre 1966 y 1969. Además esta popularidad posibilitó que Moore se retirase del cine y de la televisión, en 1959, para centrarse en apariciones públicas caracterizado 
como su personaje. En 1979, Lone Ranger Television Inc., subsidiaria de Wrather Corporation, logró, por vía legal, suspender estas "peformances", para allanar el camino al filme que se estrenaría al año siguiente (Moore, sin embargo, recuperaría sus derechos en 1985).

La nueva incursión de este héroe en el cine ha sido dirigida por Gore Verbinski (El Llanero Solitario, 2013), más centrada que sus predecesoras en Toro (Johnny Depp). Esta última producción ha conseguido desbancar a la que, hasta ahora, había sido la película más importante del personaje: la superproducción de 1981 titulada La Leyenda del Llanero Solitario, dirigida por William A. Fraker. La adaptación contaba con Klinton Spilsbury en el papel principal, y con Michael Horse, de origen indio, como Toro, más Christopher Lloyd, como el villano Bartholomew "Butch" Cavendish. En la misma película participaba Jason Robards encarnando a Ulysses Grant. La película fue un fracaso estrepitoso en su estreno comercial, pese a contar con la banda sonora del recientemente fallecido John Barry.

Vale la pena incluir algunas consideraciones sobre este filme clásico. La cinta se desarrolla durante el segundo mandato de Grant, y en una escena concreta algunos personajes recuerdan los casos de corrupción que lo caracterizaron. En la primera conversación que mantiene El Llanero con su hijo Dan, éste le habla del presidente con cierto desprecio:

- Dan Reid (DR): ¿Irás a verlo cuando llegue?

- John Reid (JR): ¿A Cavendish?

- Hermano: A Grant, el presidente. Va a venir a cazar bisontes y a dar discursos. Toda la ciudad va a ir a darle la bienvenida con banderitas. A mí me da asco.

- JR: Es el Presidente de Los Estados Unidos.

- DR: Es un falso y un borracho. iAl cuerno el presidente y al cuerno el Gobierno! Aquí no sirven para nada. En Texas los ladrones son fugitivos. En Washington, los ladrones están en el congreso.

En casos como el que se describe, la fantasía y la mitificación de los personajes históricos es un hecho que -platónicamente- roza el absurdo. En el tren, Grant se traslada hasta el sur de Texas acompañado de otras tres leyendas del viejo Oeste: el general George A. Custer (Lincoln Tate), Wild Bill Hickok (Richard Farnsworth) y Bufallo Bill Cody (Ted Flicker). Un trío que 
no dudará en unirse a los libertadores del presidente emprendiéndola a tiros con los esbirros de Cavendish. Ulysses Grant, antes de ser apresado, se despide de sus peculiares amigos alegando que se retira para escribir el discurso "que tiene que pronunciar en ese cochino pueblo". Correlativa al momento histórico en que se desenvuelve la acción, contemplamos repetidamente, durante buena parte del metraje, esta versión despótica del presidente despreciado por algunos de sus conciudadanos, pero a la que pronto superará su construcción mítica. Antes de retirarse a dormir y tras leer el discurso que va a pronunciar ante sus camaradas, Grant le recuerda a Bufalo Bill que el hecho de que estén desapareciendo los búfalos y el problema de los indios son dos cosas que no pueden tratarse a la ligera. Cuando Grant es apresado por Cavendish, éste le lee una carta con sus condiciones. En ellas vemos el reflejo de esa corrupción de la que nos habla la historia, donde se mezcla la realidad de una situación con la falsedad de unos hechos:

- Cavendish (C): Quiero su opinión.

- Grant: ¿Sí?

- C (lee la carta con sus exigencias): Al señor Hamilton Fish, Secretario de Estado: Señor, dado que los Estados Unidos no han sabido dar adecuada protección a los ciudadanos americanos, y dado que tampoco ha sabido proporcionarnos un jefe valiente y honrado, en consecuencia, quiero que se haga saber que yo, el Mayor Bartholomew "Butch" Cavendish, estoy dispuesto a retener al Presidente de los Estados Unidos como prisionero mío, hasta que se me reconozca el derecho a la propiedad sobre el territorio de Texas, citado en este documento. Más aún: exijo que este territorio se me conceda mediante Ley irrevocable proclamada por el Congreso de los Estados Unidos, antes de 30 días, a partir de la fecha de este escrito, o el señor Ulysses Grant será fusilado.

El carácter cobarde que parece adjudicar al presidente el malvado Cavendish se verá pronto desmentido con la actitud de éste, al final del filme, cuando Grant, empuñando su revólver, resuelva a tiros esta disparatada historia, redirigiendo al mismo tiempo, a ojos del espectador, sus hasta entonces dudosas cualidades por la senda del heroísmo. Un recurso, el de su osadía en el combate, que en el revestimiento del personaje histórico con las mieles de la ficción encuentra innumerables justificaciones capitulares, como por ejemplo la de la primera gran victoria unionista en la guerra, concretamente 
con la caída del Fuerte Henry, el 6 de febrero de 1862, y de Fort Donelson, el 16 de febrero del mismo año.

Cabe resaltar que gran parte de esta versión de El Llanero Solitario de 1981 se rodó en el desierto de Arizona, en los mismos parajes donde, años atrás, John Ford rodara muchos de sus clásicos westerns. Con todo, la película se centra en el capítulo piloto de la serie de televisión y el presidente, en este filme, es algo más que una anécdota: está perfectamente integrado en el guión, como personaje secundario de relevancia, tanto presencial como argumentalmente.

Como puede apreciarse, las tres secuencias muestran una visión totalmente mitificada del presidente. En la primera se le ve como a un hombre sin prejuicios que es capaz de escuchar a su enemigo, incluso ante la sospecha de que pueda tratarse de un psicópata. En la segunda reconoce sus defectos como borracho expuesto a los peligros de la política. Un reconocimiento constante, como en el diálogo extraído de La conquista del oeste, y también en comentarios en tercera persona como los que tienen lugar en Murieron con las botas puestas. Pero también es clarificador el entorno que rodea siempre las apariciones del presidente Ulysses Grant. En Río de plata le vemos siempre con la copa en la mano, en una fiesta celebrada en su honor. Si bien se diría que la escena es propia de una fiesta, lo cierto es que la imagen vuelve a repetirse en el barco varado donde John Wayne se reúne con Ulysses para hablar de su descabellado plan, esta vez en Misión de audaces. El resto de las películas mencionadas siguen el mismo patrón, de modo que a Ulysses Grant siempre se le hace aparecer con una copa y su sempiterno puro entre las manos.

A pesar de que, a partir de los años sesenta, la visión de los presidentes en el cine cambió, fruto del descontento popular motivado por la entrada de tropas americanas en la república de Vietnam, la visión mítica y cinematográfica de mandatarios como Ulysses Grant apenas ha sufrido cambios, tal y como atestigua Infierno sobre ruedas, y en la última gran producción del realizador Steven Spielberg sobre la época, Lincoln (2012), que estudiaremos a continuación. 
En la tercera secuencia, Grant es retratado como un hombre justo y visionario que es capaz de contemplar un futuro inmediato entre vencedores y vencidos, y que además no duda en atacar la corrupción pese a ser bien sabido que, durante su segundo mandato, los casos de corrupción llevados a cabo por sus familiares dentro del gobierno fueron ampliamente aireados por los grandes periódicos de la nación.

\subsection{Lincoln}

En Lincoln, de Steven Spielberg, la presencia de Ulysses Grant toma apenas cinco minutos de los más de 145 que dura el filme. En ellos, además, no siempre aparece dentro del cuadro, como en el momento en el que Abraham Lincoln (Daniel Day Lewis) habla de él en una breve escena. Para variar, esta vez no encontramos referencias a su alcoholismo, ni evidentes ni sugeridas, aunque sí aparece con su sempiterno puro y retratado con la habitual vitola de aguerrido militar, fiel a su comandante en jefe. Si bien Spielberg evita la mitificación del personaje a través de sus vicios, como hemos comprobado en otros filmes hasta la saciedad en cintas anteriores, ello no quiere decir que no eleve al personaje en cada plano, mediante su lenguaje corporal y gestual. La primera secuencia donde aparece, de hecho, refleja un encuentro con los representantes del gobierno de los Estados del Sur, que se dirigen a Washington para hablar de paz. Grant ha leído los documentos que traen y los devuelve:

- Grant (G): Caballeros, les sugiero que hagan algunos cambios a sus propuestas antes de dárselas al presidente.

- Comisionado 1: Queremos ir cuanto antes a Washington.

- Comisionado 2 (C2): ¿El señor Lincoln le ha pedido que nos diga eso?

- G: Ahí pone "garantizar la paz para nuestros dos países" y sigue en esa línea. Solo hay un país. Usted y yo somos ciudadanos de este mismo país. Yo lucho para protegerlo de rebeldes armados... De ustedes (golpea amistosamente el hombro del comisionado dos).

- C2: El señor Blair nos dijo... iQué diablos, le dijo al presidente Davis que íbamos...! (Es interrumpido por Grant).

- G: Un particular como el señor Blair puede decir lo que le plazca, ya que no tiene autoridad de ninguna clase. Si quieren hacer la paz con el presidente Lincoln, plantéense hacer correcciones. 
- C2: Si no vamos a hacer una tregua entre naciones en guerra, ¿qué diablos hemos venido a hacer aquí? ¿Qué es lo que vamos a tratar?

- G: Su rendición.

En la secuencia posterior, que se desarrolla justo a continuación, Grant camina con algunos de sus hombres mientras su voz en off verifica un telegrama que envía al presidente Lincoln.

- Grant (voz en off mientras le vemos caminando): Oficina telegráfica del ejército. Departamento de Guerra para Abraham Lincoln, presidente de los Estados Unidos de América. 20 de enero de 1865. Le expongo confidencialmente que estoy convencido, tras conversar con los comisionados, de que sus intenciones son buenas y que desean sinceramente restaurar la paz y la Unión. Mi temor es que, al regreso a su tierra, sin ninguna manifestación de interés por parte de autoridad alguna... (se produce un fundido encadenado y ahora es el vicepresidente quien está leyendo el telegrama enviado por Ulysses Grant al presidente Lincoln).

- Vicepresidente (continuando con la lectura del telegrama que tiene en su mano): Señor Lincoln, les deje una influencia negativa. Lamentaría profundamente que le fuera imposible entrevistarse con ellos. Quedo a la espera de sus instrucciones. Ulysses S. Grant, Teniente General de las Fuerzas Armadas, Ejército de Los Estados Unidos.

- Lincoln: Tras cuatro años de guerra, y casi 600.000 vidas perdidas, está convencido de que ya podemos acabar con la guerra (se queda meditando unos instantes). Mi confianza en él es plena y profunda.

La conversación continúa con los dos mandatarios planeando cuál es la mejor fórmula para terminar con el conflicto sin tener que retirar la enmienda para la abolición de la esclavitud en el parlamento.

Las dos secuencias lucen plenas de significado. Son hechos que la Historia relata, y Spielberg trata de mostrarlos de una forma escéptica y nada partidista, pero el cine siempre lo es, y tiende a mostrar la ideología de los realizadores. La forma en que Spielberg muestra a Ulysses Grant discurre de nuevo por la senda del mito histórico; pule siempre una imagen de seguridad, templanza y fidelidad a Lincoln, ora por el modo en que el líder camina acompañado por sus oficiales, ora por la pose de seguridad que toma al hablar con los comisionados, o bien a través de la respuesta transcrita a Lincoln.

Queda todavía una última aparición de Grant, como corolario a nuestras argumentaciones: nos encontramos en Appomattox Courthouse, Estado de Virginia, el 9 de abril de 1865. Un soldado acerca el caballo blanco del general Lee a las puertas de la cabaña que hace las funciones de cuartel 
general de la plana mayor del ejército de la Unión. Lee baja los seis peldaños, y es ayudado a subir al caballo. Desde su montura ve salir al pórtico a la plana mayor del General Ulysses Grant, y ambos se miran durante unos instantes. Grant baja entonces las escaleras y se sitúa a la izquierda del caballo de Lee; deja de fumar y se quita el sombrero. Toda su plana mayor imita el gesto y permanecen inmóviles mientras Lee se quita el suyo y tira de las riendas de su caballo hacia atrás, sin dar la espalda a los oficiales. Se trata sin duda de una hermosa escena en la que no hay diálogo alguno; un minuto y quince segundos que escenifican el final de la guerra sin odios y sin rencores.

Lo primero que trasluce en ella es la humanidad de los dos generales responsables de materializar los deseos de sus respectivos presidentes. Ulysses Grant, como se manifestó en la secuencia anterior, es el brazo ejecutor de Lincoln, y en los pocos instantes en que permanece en pantalla es mostrado como un hombre fiel y eficaz, cosa que Lincoln reconoce, cuando, en otro tramo de la cinta, manifiesta la confianza que siempre ha tenido en este hombre.

El segundo instante destacable, sin duda, es la visión de un oficial eficaz en su cometido y respetuoso con su enemigo, como se demuestra en el gesto ceremonial consistente en bajar las escaleras y quitarse el sombrero frente a Lee. $\mathrm{Y}$ un tercero apelaría al mismo tiempo a la visión de un general respetado tanto por oficiales como por sus enemigos, y que puede comprobarse en la imitación de su plana mayor al despojarse del sombrero una vez que lo ha hecho su general, y la empatía, con el mismo gesto a su vez, del general Lee, ante la muestra de respeto de quien ha sido su verdugo.

\section{Conclusiones}

Hasta ahora, todas las películas mencionadas apenas llegan a superar los 10 minutos de presencia total en pantalla de Ulysses Grant, pero en todas forma parte del momento de inflexión necesario para que el protagonista sufra el cambio transformador propio de cualquier filme de aventuras. Una trascendencia que tampoco deja de llamar la atención, toda vez que, como se 
ha dicho, se trata de un presidente que, en sus dos legislaturas, mostró una franca inoperancia, amén de una escasa lucidez para las intrigas que le han hecho pasar a la Historia como un mandatario con pocas aportaciones al desarrollo del país. Ni siquiera en lo tocante a la construcción del ferrocarril, ya que, durante su segundo mandato, cabe recordar, Grant se vio involucrado en el escándalo del Credit Mobilier, al descubrirse que una empresa encargada de la construcción del Union Pacific obtuvo grandes beneficios al cobrar más del doble de los costes reales de construcción, desviando además un gran número de acciones a congresistas con el objetivo de frenar una investigación abierta por el Congreso para resolver el asunto.

\section{Referencia bibliográficas}

Astre, G-A, Hoarau, A-P. (1997). El universo del western. Madrid: Fundamentos.

Doval, G. (2009). Breve historia de la Conquista del Oeste. Madrid: Ediciones Nowtilus.

Everson, W. (1992). El western de Hollywood. Barcelona: Paidós Ibérica.

McBride, J. (2004). Tras la pista de John Ford. Madrid: T\&B Editores.

Grant, U. (2002). Personal Memoirs of U.S. Grant. Recuperado de: http://www-

tc.pbs.org/wgbh/americanexperience/media/uploads/special_feature s/download_files/memoirs.pdf

Sánchez-Bayón, A. (2005, septiembre). Idiosincrasia de la identidad nacional y del modelo sociocultural estadounidense según el influjo de sus élites político-jurídicas (a vueltas con la religión civil). Comunicación presentada en el VII Congreso Español de Ciencia Política y de la Administración: Democracia y Buen Gobierno: AECPA, 2005, 21-23 de septiembre. Madrid: Universidad Complutense de Madrid. Recuperado de: http://www.aecpa.es/uploads/files/congresos/congreso_07/areao6/ GT26/SANCHEZ-BAYON-Antonio\%28UCM\%29.pdf

Cómo citar: Iturrate, L.F. y Fuentefría, D. (2015). "Las ocho vidas de Ulysses Grant: el mito y el relato cinematográfico". Fotocinema. Revista científica de cine $y$ fotografía, 11, pp. 112-145. Disponible: http://www.revistafotocinema.com/ 